\title{
SILAGENS DE MILHO (zea mays, L) OU CAPIM ELEFANTE(Pennisetum purpureum, Schum.) cv. NAPIER PARA ALIMENTAÇÃO DE TERNEIROS DE CORTE CONFINADOS ${ }^{1}$
}

\author{
CORN SILAGE OR ELEPHANT GRASS SILAGE FOR BEEF CALVES FEEDING
}

\author{
Rui de Castro Pilar ${ }^{2}$ João Restle ${ }^{3} \quad$ Glênio Lopes dos Santos ${ }^{3}$ \\ José Henrique Souza da Silva ${ }^{3}$
}

\section{RESUMO}

Foi avaliado o desempenho em confinamento, por um período de 84 dias, de terneiros de corte alimentados com uma das seguintes dietas: $T_{1}$ - silagem de milho (zea mays, L) + concentrado $(32,65 \%)$, $\mathrm{T}_{2}$ - silagem de capim elefante (Pennisetum purpureum, Schum.) cultivar napier + concentrado $(33,36 \%)$ e $\mathrm{T}_{3}$ - silagem de napier + concentrado $(48,27 \%)$. O tipo de dieta não influenciou ( $P \geq 0,2059)$ no consumo médio diário de matéria seca. As dietas $\mathrm{T}_{3}$ e $T_{1}$ proporcionaram ganhos de peso médio diário similares e que foram superiores $(P<0,0450)$ ao proporcionado pela $T_{2}$. Com relação a conversão alimentar, não houve diferença ( $P \geq 0,1292)$ entre tratamentos.

Palavras-chave: silagem, milho, napier, terneiros, confinamento.

\section{SUMMARY}

The experiment evaluated the performance of beef calves confined during 84 days and fed with one of the following diets: $T_{1}$ - corn silage plus concentrate
(32.65\%, dry matter basis), $\mathrm{T}_{2}$ - elephant grass (Pennisetum purpureum, Schum.) napiergrass silage plus concentrate (33.36\%) and $\mathrm{T}_{3}$ - napiergrass silage plus concentrate $(48.27 \%)$. Daily dry matter consumption was not affected $(P \geq 0.2059)$ by the type of diet. Average daily gain was similar for $T_{1}$ and $T_{3}$ calves, and higher $(P<0.0450)$ than observed for $T_{2}$ calves. Feed conversion was not affected $(P \geq 0.1292)$ by the type of diet.

Key words: silage, corn, elephant grass, calves, feedlot.

\section{INTRODUÇÃO}

No Rio Grande do Sul, a pecuária de corte é explorada basicamente de forma extensiva, onde a alimentação dos animais depende quase que exclusivamente das pastagens naturais. $O$ reduzido crescimento destas pastagens naturais durante o inverno, aliado a baixa qualidade, determinam uma carência alimentar para os animais, o que traz como conseqüência baixos índices de produtividade na pecuária de corte.

\footnotetext{
'Parte da Dissertação de Mestrado, apresentada pelo primeiro autor ao Curso de Pós-Graduação em Zootecnia da Universidade Federal de Santa Maria (UFSM), para obtenção do Grau em Mestre em Zootecnia.

${ }^{2}$ Zootecnista MSc, Pesquisador da FAPERGS (Recém-Mestre) em Produção Animal, Departamento de Zootecnia, UFSM.

${ }^{3}$ Engenheiro Agrônomo, Professor Titular, PhD, Departamento de Zootecnia, UFSM, 97119-900 - Santa Maria, RS. 
A utilização de pastagens cultivadas é uma forma de suprir os animais com uma alimentaçăo mais adequada durante o inverno. Outra alternativa, para fornecer aos animais uma dieta mais adequada durante os períodos de carência, é o fornecimento de alimentos no cocho. Esta prática de alimentação, que vem crescendo nos últimos anos, pode ser realizada tanto na forma de suplementação a campo, bem como em sistema de confinamento.

Segundo MÜHLBACH (1989), silagem é um alimento de composiçăo química relativamente homogênea e, comı na prática, o fornecimento aos animais pode ser controlado, pode-se através do uso estratégico nos períodos de escassez, evitar o grande problema da pecuária bovina que é o da sazonalidade da produçăo, tanto de carne como de leite.

Existem na literatura científica, muitos resultados de trabalhos de pesquisa sobre a utilização da silagem de milho para alimentação de animais confinados. Na Universidade Federal de Santa Maria, vários trabalhos de pesquisa têm testado ou utilizado a silagem de milho para animais confinados (BRONDANI et al., 1986; MARTINS et al., 1988; FELTEN et al., 1988; RODRIGUES et al., 1989; QUADROS \& RESTLE, 1989; RESTLE et al., 1990a; RESTLE et al., 1990b; SILVA \& RESTLE, 1990; SILVA et al., 1991).

Com relação a utilização de silagem de capim elefante para animais confinados, praticamente não existem dados de pesquisa no Rio Grande do Sul. Esta constatação, reforça a necessidade de se desenvolver trabalhos de pesquisa a fim de estudar o potencial forrageiro desta espécie, quando ensilada.

VILELA (1990), em uma revisão sobre a utilização do capim elefante na forma de forragem conservada, como silagem, afirma que o corte deverá ocorrer quando a idade da planta estiver entre $56 \mathrm{e}$ 105 dias e com altura entre 160 e $185 \mathrm{~cm}$. Desta forma, associa-se produção e qualidade para a obtenção de maiores rendimentos.

O presente estudo teve como objetivos: avaliar e comparar a utilização, na alimentaçăo de terneiros de corte, das silagens de milho e capim elefante cv. napier com diferentes níveis de concentrado.

\section{MATERIAL E MÉTODOS}

O experimento foi realizado nas dependências do Departamento de Zootecnia da Universidade Federal de Santa Maria - RS.

Foram comparados os seguintes tratamentos: $\mathrm{T}_{1}$ - silagem de milho + concentrado $(32,65 \%), \mathrm{T}_{2}$ silagem de napier + concentrado $(33,36 \%)$ e $T_{3}$ - silagem de napier + concentrado $(48,27 \%)$.
Foram utilizados 12 animais cruza Blonde D'Aquitaine $\times$ Caracu, machos, castrados, com 10 meses de idade e peso vivo médio inicial de $151 \mathrm{~kg}$, sendo 4 animais por tratamento. Esses temeiros foram criados extensivamente em campo nativo e foram desmamados no momento do início do trabalho.

Utilizou-se 6 piquetes, área de $50 \mathrm{~m}^{2}$ cada, local onde os terneiros permaneceram confinados em grupos de 2 animais por piquete. Esses continham bebedouros com bóia automática e uma cobertura protetora na área onde se encontravam os comedouros (cochos comuns de madeira medindo $3,5 \mathrm{~m}$ de comprimento, $0,60 \mathrm{~m}$ de largura e $0,25 \mathrm{~m}$ de profundidade).

Antecedendo ao início do experimento, os animais receberam a alimentação experimental de adaptaçăo por 16 dias. Após, os animais foram pesados e ingressaram no período experimental no dia 7 de agosto de 1990 e que perdurou até 30 de outubro do mesmo ano.

Durante todo o período experimental, o concentrado para $0 T_{1}$ e $T_{2}$ foi composto por grão de milho moído $(67 \%)+$ farinha de carne $(20 \%)+$ farelo de soja $(9 \%)+$ uréia $(38 \%)+$ farinha de ostra $(1 \%)$. Para o $T_{3}$ o concentrado foi composto por grão de milho moído $(50 \%)+$ farinha de carne $(14 \%)+$ farelo de soja $(2 \%)$ + farinha de ostra (1\%) + farelo de arroz (31\%).

Ensilou-se a rebrota primaveril do napier estabelecido há três anos e que fora cortado durante o inverno. A silagem foi feita em 22 de dezembro de 1989 , quando as plantas tinham uma altura em torno de $1,80 \mathrm{~m}$ e um teor de MS de aproximadament $\epsilon 22 \%$. Foi obtida uma produção de 22 te massa verde (MV) por ha.

A silagem de milho cultivar pionner 3216 foi feita em 10 de abril de 1990, ensilando-se plantas com 130 dias após o plantio e com um teor de 33\% de MS. Foi obtida uma produção de $30 t$ de MV/ha.

Periodicamente, foram coletadas amostras dos alimentos utilizados, para a realização de análises laboratoriais que incluíram todas as determinações do método de WEENDE (AOAC, 1984), bem como da digestibilidade in vitro da MS (DIVMS) e da matéria orgânica (DIVMO), pelo método TILLEY \& TERRY (1963). A concentração de energia digestível (ED), das silagens, foi estimada a partir da DIVMO, segundo ARC (1980).

A digestibilidade in vitro da MS (DMS) e da MO (DMO) das dietas, foram determinadas através de um ensaio com ovinos em gaiolas metabólicas. A concentração de ED, das dietas, foi estimada a partir da DMO (ARC, 1980).

Os consumos médios de proteína bruta (CPB), referentes ao período experimental (Tabela 2) foram obtidos pela diferença entre o teor de PB na MS 
das dietas oferecidas e o teor de PB na MS das sobras.

Os consumos médios de energia líquida para ganho (CELg, Tabela 2) foram obtidos a partir do consumo de MS realizado pelos animais subtraindo a MS para manutençăo e multiplicando pela concentraçăo de energia que cada $\mathrm{kg}$ de MS forneceu para ganho, de acordo com as dietas (calculado pela equaçăo estipulada pelo NRC, 1984).

Usou-se o delineamento em blocos ao acaso com 2 repetiçőes, sendo o critério de bloqueamento o balanceamento dos pesos iniciais dos animais. Cada unidade experimental foi composta por 2 animais. Avaliou-se o potencial das diferentes silagens através dos parâmetros consumo voluntário de matéria seca (CMS), ganho de peso médio diário (GMD) e conversão alimentar (CA).

\section{RESULTADOS E DISCUSSÃO}

As silagens de milho e napier apresentaram, respectivamente, valores percentuais de matéria seca de 28,01 e 20,94. Na matéria seca os respectivos valores foram: proteína bruta 8,02 e 9,84\%; fibra bruta 20,61 e 35,42 . Digestibilidade in vitro da matéria orgânica 53,98 e 39,03\%; energia digestivel estimada 2,453 e 1,773 kcal/g MS e pH de 3,95 e 4,46.

A composição bromatológica e a ED estimada, das dieias, são apresentadas na Tabela 1. A proporção de concentrado na dieta havia sido estipulada em 30\% ( $T_{1}$ e $\left.T_{2}\right)$ e $48 \%\left(T_{3}\right)$. Ocorre que as amostras das silagens, coletadas ao longo do experimento, apresentaram teores de PB superiores aos obtidos preliminarmente. Também as proporçőes de concentrado nas dietas foram superiores $\left(T_{1}: 32,65 \%\right.$ e $\left.T_{2}: 33,36 \%\right)$ as estimadas inicialmente que era de $30 \%$. Em função disto, no $T_{1}$ e $T_{2}$ as dietas apresentaram proporçðes mais elevadas de PB do que aquelas inicialmente estipuladas em $14 \%$.

Os consumos médios diários de MS (CMS), de PB (CPB) e de energia líquida para ganho (CELg), durante o período experimental, săo sumariados na Tabela 2.

O tipo de dieta (Tabela 2) não influenciou $(P \geq 0,05)$ no consumo de MS tanto expresso em $\mathrm{kg}$ por animal (kg/an/dia), em $\mathrm{kg}$ por $100 \mathrm{~kg}$ de peso vivo ( $\mathrm{kg} / 100 \mathrm{~kg} P V / \mathrm{dia})$ como em gramas por unidade de tamanho metabólico (g/UTM/dia).

Os valores de consumo de MS (kg/an/dia) foram similares aos obtidos por MARTINS et al. (1988) 4,33kg; QUADROS et al. (1990) 4,70kg; TOWNSEND (1991) $4,30 \mathrm{~kg}$ e RESTLE \& ALVES FILHO (1992)
$4,75 \mathrm{~kg}$, trabalhando com animais da mesma categoria (terneiros de 10 meses) em confinamento, alimentados com silagem mais concentrado. O consumo de MS $(\mathrm{kg} / 100 \mathrm{~kg} \mathrm{PV} / \mathrm{dia})$ foi próximo dos valores encontrados por FERREIRA et al. (1988) 2,18\%; TOWNSEND (1991) 2,23\% e HENRIQUE et al. (1992) 2,32\%, com terneiros em confinamento, alimentados à base de silagem como volumoso. Quando os valores de consumo de MS foram expressos em gramas por unidade de tamanho metabólico (g/UTM/dia), a média foi similar aos obtidos por QUADROS et al. (1990) 82,40g e TOWNSEND (1991) 83,0g, porém, menor que a média encontrada por RESTLE \& ALVES FILHO (1992) de $95,30 \mathrm{~g}$ por ocasiåo do confinamento de animais da mesma categoria.

No presente trabalho foram consumidas, em média $0,9 \mathrm{~kg}$ de $\mathrm{PB}$ para cada $\mathrm{kg}$ de ganho de peso, e que está bem acima dos valores preconizados pelo NRC (1984).

Numericamente, os consumos de ELg (Tabela 2) no $T_{1}$ e $T_{3}$ foram similares e superiores, em média, $20,88 \%$ em relação ao $\mathrm{T}_{2}$. Porém, năo houve diferença significativa $(P \geq 0,05)$ entre as diferentes dietas.

$\mathrm{O}$ consumo de ELg dos terneiros, foi em média $15,25 \%$ menor que a ELg preconizada pelo NRC (1984) para conferir os mesmos ganhos de peso, concordando com os resultados de SALVADOR (1980), PIRES (1991), TOWNSEND (1991) e PASCOAL (1992).

Tabela 1 - Valores percentuais de matéria seca (MS), proteina bruta (PB), fibra bruta (FB), digestibilidade in vi tro da matéria orgânica (DMO) e energia digestivel (ED) estimada das dietas experimentais, conforme os tratamentos.

\begin{tabular}{lccccc}
\hline $\begin{array}{l}\text { TRATA- } \\
\text { MENTOS }\end{array}$ & MS $^{*}$ & PB $^{*}$ & FB* $^{*}$ & DMO & $\begin{array}{c}\text { ED } \\
\text { (kcalkg MS) }\end{array}$ \\
\hline$T_{1}^{*}$ & 35,96 & 16,25 & 14,43 & $66,90 \mathrm{a}$ & 3.040 \\
$\mathrm{~T}_{2}$ & 28,87 & 18,87 & 24,16 & $61,65 \mathrm{ab}$ & 2.801 \\
$\mathrm{~T}_{3}$ & 33,07 & 14,42 & 19,17 & $63,54 \mathrm{ab}$ & 2.887 \\
\hline MÉDIA & 32,63 & 16,51 & 19,25 & 64,03 & 2.909
\end{tabular}

\footnotetext{
* Expresso no material como foi oferecido

* Expresso na matéria seca

* $T_{1}$ - Silagem de milho + concentrado $(32,65 \%)$

$\mathrm{T}_{2}$ - Silagem de napier + concentrado $(33,36 \%)$

$\mathrm{T}_{3}$ - Silagem de napier + concentrado $(48,27 \%)$

$a, b$ Médias, na coluna, seguidas pela mesma letra năo diferem entre si (Tukey, $P \geq 0,05$ ).
} 
Tabela 2 - Consumos médios diários de matéria seca (CMS), proteina bruta (CPB) e energia liquida para ganho (CELg), conforme os tratamentos.

\begin{tabular}{|c|c|c|c|c|c|}
\hline \multirow{2}{*}{$\begin{array}{l}\text { TRATA- } \\
\text { MENTOS }\end{array}$} & \multicolumn{3}{|c|}{ CMS } & \multirow{2}{*}{$\begin{array}{l}\text { CPB } \\
\text { (g/an) }\end{array}$} & \multirow{2}{*}{$\begin{array}{c}\text { CELg } \\
\text { (Mcal/an }\end{array}$} \\
\hline & $\mathrm{kg} / \mathrm{an}$ & $\mathrm{kg} / 100 \mathrm{~kg}$ & g/UTM & & \\
\hline $\mathrm{T}_{1}^{*}$ & 4,04 & 2,19 & 80,50 & $679 \mathrm{~b}$ & 1,634 \\
\hline $\mathrm{T}_{2}$ & 4,24 & 2,32 & 85,50 & $784 a b$ & 1,309 \\
\hline $\mathrm{T}_{3}$ & 4,49 & 2,42 & 89,00 & $821 a^{*}$ & 1,675 \\
\hline MÉDIA & 4,26 & 2,31 & 85,00 & 761 & 1,539 \\
\hline$F$ & 3,86 & 2,54 & 2,70 & 29,54 & 3,34 \\
\hline$P>F$ & 0,2059 & 0,2827 & 0,2700 & 0,0327 & 0,2307 \\
\hline CV (\%) & 3,81 & 4,33 & & 2,51 & 9,95 \\
\hline
\end{tabular}

- $\mathrm{T}_{1}$ - Silagem de milho + concentrado $(32,65 \%)$

$\mathrm{T}_{2}$ - Silagem de napier + concentrado $(33,36 \%)$

$\mathrm{T}_{3}$ - Silagem de napier + concentrado $(48,27 \%)$

- Médias, na coluna, seguidas pela mesma letra não diferem entre si (Tukey, $P \geq 0,05$ )

As médias de peso vivo inicial e final, ganho de peso total e ganho diário $(\mathrm{kg})$, bem como a conversão alimentar avaliada durante os 84 dias de confinamento, para os três tratamentos, estão expostos na Tabela 3.

$O$ tipo de dieta afetou $(P<0,05)$ o ganho de peso médio diário (GMD) dos animais. Os tratamentos $\mathrm{T}_{3}$ e $T_{1}$ proporcionaram GMD similares (Tabela 3) e que foram em média $16,30 \%$ superiores $(P<0,045)$ ao proporcionado pelo $T_{2}$.

Os animais dos tratamentos $T_{1}$ e $T_{3}$ que proporcionaram os maiores ganhos de peso, também foram os que tiveram os maiores consumos de energia líquida para ganho (Tabela 2), consumindo em média $20,88 \%$ mais que os animais do tratamento $T_{2}$.

Comparando as dietas com o mesmo nível de concentrado, se observou que a dieta contendo silagem de napier $\left(T_{2}\right)$, cortado com aproximadamente 90 dias de rebrote primaveril, proporcionou um GMD $16,06 \%$ inferior ao proporcionado com a dieta contendo silagem de milho $\left(T_{1}\right)$ isto, certamente foi uma conseqüência da menor concentração de energia digestível da dieta do $T_{2}$ (Tabela 1). Essa diferença no GMD em $16,06 \%$ entre o proporcionado com a dieta contendo silagem de napier $\left(T_{2}\right)$ e com silagem de milho $\left(T_{1}\right)$ foi inferior ao observado por HENRIQUE et al. (1992), e que foi de $22,90 \%$, trabalhando com essa categoria animal. O GMD proporcionado pela dieta contendo silagem de milho foi maior do que o encontrado por MARTINS et al. (1988) $0,710 \mathrm{~kg}$ e menor do que o obtido por JUSTO et al. (1989) e HENRIQUE et al. (1992), de 1,103 e $1,344 \mathrm{~kg}$, respectivamente, também com terneiros alimentados com silagem de milho mais concentrado. Enquanto que o GMD proporcionado com a dieta contendo silagem de napier $\left(T_{2}\right)$ foi similar ao encontrado por VILELA et al. (1990), 0,727 e menor do que o encontrado por HENRIQUE et al. (1992), 1,036, também com essa mesma categoria animal, alimentada com silagem de capim elefante mais concentrado.

Tabela 3 - Peso vivo inicial e final, ganho total e diário, bem como a conversáo alimentar, de acordo com os tratamentos.

\begin{tabular}{|c|c|c|c|c|c|}
\hline \multirow{2}{*}{ DIETAS } & \multicolumn{2}{|c|}{ PESO VIVO (kg) } & \multicolumn{3}{|c|}{ GANHO DE PESO (kg) } \\
\hline & INICIAL & FINAL & TOTAL & DIÁRIO & ALIMENTAR \\
\hline $\begin{array}{l}\mathrm{T}_{1}^{\cdot} \\
\mathrm{T}_{2} \\
\mathrm{~T}_{3}\end{array}$ & $\begin{array}{l}146,50 \\
151,50 \\
148,50\end{array}$ & $\begin{array}{l}221,25 \\
214,25 \\
223,75\end{array}$ & $\begin{array}{l}74,75 \\
62,75 \\
72,25\end{array}$ & $\begin{array}{l}0,890 a^{\circ} \\
0,747 \text { b } \\
0,895 \text { b }\end{array}$ & $\begin{array}{l}4,55 \\
5,73 \\
5,02\end{array}$ \\
\hline MÉDIA & 148,83 & 219,75 & 69,92 & 0,844 & 5,10 \\
\hline $\begin{array}{l}F \\
P>F \\
C V(\%)\end{array}$ & & & & $\begin{array}{c}21,22 \\
0,0450 \\
3,06\end{array}$ & $\begin{array}{l}6,74 \\
0,1292 \\
6,34\end{array}$ \\
\hline
\end{tabular}

- $T_{1}$ - Silagem de milho + concentrado $(32,65 \%)$

$\mathrm{T}_{2}$ - Silagem de napier + concentrado $(33,36 \%)$

$\mathrm{T}_{3}$ - Silagem de napier + concentrado $(48,27 \%)$

- Médias, na coluna, seguidas pela mesma letra não diferem entre si (Tukey, $P \geq 0,05$ ).

Os resultados de ganho de peso, mostram que o capim elefante pode ser utilizado na confecção de silagem para posterior alimentação de bovinos. No entanto, para proporcionar o mesmo ganho de peso que a silagem de milho, os animais devem receber uma maior proporção de concentrado na dieta. Para atingir o mesmo ganho de peso que os animais alimentados com a silagem de milho, foi necessário aumentar a proporção de concentrado na dieta de $32,65 \%$ para $48,27 \%$, o que representou um aumento de $47,84 \%$ no concentrado.

Com relação a conversão alimentar (Tabela 3), numericamente os animais alimentados com silagem de milho foram mais eficientes, porém, não houve diferença significativa $(P \geq 0,05)$ entre os tratamentos. 
A conversão alimentar de 4,55 para os animais alimentados com silagem de milho $\left(T_{1}\right)$ foi melhor que as encontradas por MARTINS et al. (1988) 5,90 e HENRIQUE et al. (1992) de 5,72 confinando terneiros alimentados com silagem de milho mais concentrado. A média geral de conversão alimentar (Tabela 3) obtida no presente experimento, foi próxima as encontradas por QUADROS et al. (1990), TOWNSEND (1991) e RESTLE \& ALVES FILHO (1992) sendo, respectivamente, 4,90; 4,70 e 4,99 com essa categoria animal em confinamento.

\section{CONCLUSÕES}

Nas condiçס̃es em que foi realizado o presente experimento, pode-se concluir que:

- O ganho de peso médio diário (GMD) proporcionado pela dieta contendo silagem de napier é inferior ao proporcionado pela dieta contendo silagem de milho. Porém, elevando o nível de concentrado em $47,84 \%$ na dieta com silagem de napier, pode-se obter ganhos similares.

\section{REFERÊNCIAS BIBLIOGRÁFICAS}

ASSOCIATION OF OFFICIAL AGRICULTURAL CHEMISTS - A.0.A.C. Official methods of analysis. 14 ed. Washington, D.C., 1984, $1141 \mathrm{p}$.

AGRICULTURAL RESEARCH COUNCIL - A.R.C. The nutrient requeriments of ruminants livestock. Technical Review by Agricultural Research Council Warking Patry. London, 1980, 351 p.

BRONDANI, I.L., RESTLE, J., KEPLIN, L.A. et al. Efeito da utilizaçăo dos volumosos cana-de-açúcar e silagem de milho no desempenho de novilhos da raça Charoles, mantidos em confinamento. In: REUNIÃO ANUAL SOCIEDADE BRASILEIRA DE ZOOTECNIA, 1986, Campo Grande, MS, Anais... Campo Grande, Sociedade Brasileira de Zootecnia, 1986, p. 90, 427 p.

FELTEN, H.G., RESTLE, J., QUADROS, A.R.B. et al. Desempenho de dois grupos genéticos de bovinos e suas cruzas, em regime de confinamento. In: REUNIÃO ANUAL SOCIEDADE BRASILEIRA DE ZOOTECNIA, 1988, Viçosa, MG. Anais... Viçosa, Soc Bras Zootec, 1988, p. 241, 342 p.

FERREIRA, J.J., MARQUES NETO, J., MIRANDA, C.S. de. Efeito da associaçăo de capim elefante (Pennisetum purpureum, Schum.) cv. cameron e milho na qualidade de silagem e desempenho de novilhas. Rev Soc Bras Zootec, Viçosa, MG, v. 17, n. 3, p. 268-279, 1988.

HENRIQUE, W., LEME, P.R., JUSTO, C.L., et al. Uso da silagem de milho ou de capim elefante e da sacharina, como substituto parcial do concentrado, na engorda de bovinos em confinamento. In:
REUNIÃO ANUAL DA SOCIEDADE BRASILEIRA DE ZOOTECNIA, 1992, Lavras, MG. Anais... Lavras, Sociedade Brasileira de Zootecnia, 1992, p. 149, 576 p.

JUSTO, C.L., COUTINHO FILHO, J.L.V., SIQUEIRA, P.A., et a!. Utilizaçăo de uréia na dieta de bezerros desmamados Santa Gertrudis, em confinamento. In: REUNIÃO ANUAL SOCIEDADE BRASILEIRA DE ZOOTECNIA, 1989, Porto Alegre, RS. Anais...Porto Alegre, Sociedade Brasileira de Zootecnia, 1989, p. $159,461 \mathrm{p}$.

MARTINS, J.D., RESTLE, J., LANÇANOVA, J.A.C. Desempenho de terneiros de corte alimentados com silagem ou pastagem cultivada. In: REUNIÃO ANUAL SOCIEDADE BRASILEIRA DE ZOOTECNIA, 1988, Viçosa, MG. Anais... Viçosa, Sociedade Brasileira de Zootecnia, 1988, p. 285, 342 p.

MÜHLBACH, P.F. Valor nutritivo de silagens e sua utilizaçăo para bovinos. In: SEMANA DA ATUALIZAÇÃO EM BOVINOCULTURA: Alimentaçăo e nutriçăo de bovinos, 1989, Lages, SC. Anais... Lages, EPASC, 1989. p. 143-151, 318 p.

NATIONAL RESEARCH COUNCIL - N.R.C. Nutrient requeriments of beef cattle. Washington, D.C., 1984, ed. 6, 90 p.

PASCOAL, L.L. Efeito da proteina de alta ou baixa degradabilidade ruminal associada a cana-de-açúcar ou ao capim napier na alimentaçăo de bovinos confinados. Santa Maria - RS. 159 p. Tese (Mestrado em Zootecnia) - Curso de Pós-Graduaçăo em Zootecnia, Universidade Federal de Santa Maria. 1992.

PIRES, C.C. Exigências de proteína, energia e macro elementos minerais (Ca, P, Mg, Na e K) de bovinos năo castrados de trés grupos genéticos. Viçosa - MG, 125 p. Tese (Doutorado em Zootecnia) - Curso de Doutorado em Zootecnia, Universidade Federal de Viçosa. 1991.

QUADROS, A.R.B., RESTLE, J. Desempenho de novilhos da raça Hereford $(H), 5 / 8 \mathrm{H} 3 / 8$ Nelore $(\mathrm{N}), 1 / 2 \mathrm{~h} 1 / 2 \mathrm{~N}$ e $1 / 4 \mathrm{H} 3 / 4 \mathrm{~N}$, em regime de confinamento. In: REUNIÃO ANUAL SOCIEDADE BRASILEIRA ZOOTECNIA, 1989, Porto Alegre, RS, Anais... Porto Alegre, Sociedade Brasileira de Zootecnia, 1989, p. 361, $461 \mathrm{p}$.

QUADROS, A.R.B. de, RESTLE, J., SANCHEZ, L.M.B. Desempenho em confinamento de bovinos de diferentes idades alimentados com diferentes fontes protéicas. In: REUNIÃO ANUAL SOCIEDADE BRASILEIRA DE ZOOTECNIA, 1990. Campinas, SP. Anais... Campinas, Sociedade Brasileira de Zootecnia, 1990, p. $17,813 p$.

RESTLE, J., ALVES FILHO, D.C..Confinamento de terneiros inteiros ou castrados de diferentes grupos genéticos. In: REUNIÃO ANUAL SOCIEDADE BRASILEIRA DE ZOOTECNIA, 1992, Lavras, MG. Anais... Lavras, Sociedade Brasileira de Zootecnia, 1992. p. 186,576 p.

RESTLE, J., SILVA, L.C.R., DALLA PORTA, M.A. Desempenho de vacas de corte submetidas a diferentes manejos durante a terminação em confinamento. In: REUNIÃO ANUAL SOCIEDADE BRASILEIRA DE ZOOTECNIA, 1990, Campinas, SP, Anais... Campinas, Sociedade Brasileira de Zootecnia, 1990a, p. 354, 813 p.

RESTLE, J., SOUZA, E.V.T., NUCCI, E.P.D. et al. Desempenho de bovinos e bubalinos alimentados com diferentes fontes de volumosos. In: REUNIÃO ANUAL SOCIEDADE BRASILEIRA DE 
Pilar et al.

ZOOTECNIA, 1990, Campinas, SP, Anais... Campinas, Sociedade Brasileira Zootecnia, 1990b, p. 106, 813 p.

RODRIGUES, L.C., RESTLE, J., SANCHEZ, L.M.B. Diferentes tipos de alimentaçăo na terminaçăo de novilhos de corte. In: REUNIÃO ANUAL SOCIEDADE BRASILEIRA DE ZOOTECNIA, 1989, Porto Alegre, RS, Anais... Porto Alegre, Sociedade Brasileira de Zootecnia, 1989, p. 169, 461 p.

SALVADOR, M. Exigéncias de energia e proteína para engorda de novilhos azebuados. Viçosa - MG. 70 p. Tese (Mestrado em Zootecnia) - Curso de Pós-Graduação em Zootecnia, Universidade Federal de Viçosa. 1980.

SILVA, L.C.R., RESTLE, J. Desempenho de vacas de dois grupos genéticos, terminadas em regime de confinamento. In: REUNIÃO ANUAL SOCIEDADE BRASILEIRA DE ZOOTECNIA, 1990, Campinas, SP, Anais... Campinas, Sociedade Brasileira de Zootecnia, 1990, p. 474, 813 p.

SILVA, L.C.R., RESTLE, J., LUPATINI, G.C. Utilização de diferentes tipos de silagem como fontes de volumoso na terminação de novilhos em confinamento. In: REUNIÃO ANUAL SOCIEDADE BRASILEIRA DE ZOOTECNIA, 1991, João Pessoa, PB, Anais...
Joâo Pessoa, Sociedade Brasileira de Zootecnia, 1991, p. 278, 719 p.

TILLEY, L.M., TERRY, R.S.A. Two-stage technique for the in vitro digestion of forage crops. Journal of British Grassland Society. Hurley, v. 18, n. 121, p. 104-111, 1963.

TOWNSEND, M.R. Desempenho em confinamento de diferentes categorias animais e características de carcaça e da carne de novilhos e vacas. Santa Maria - RS. 123 p. Tese (Mestrado em Zootecnia) - Curso de Pós-Graduaçăo em Zootecnia, Universidade Federal de Santa Maria. 1991.

VILELA, D. Utilização do capim elefante na forma de forragem conservada. In: SIMPÓSIO SOBRE CAPIM ELEFANTE, 1990, Juiz de Fora, MG. Anais... Ed. por Limério de Almeida Carvalho e outros, Coronel Pacheco, MG, EMBRAPA - CNPGL, 1990, p. 89$131,221 \mathrm{p}$.

VILELA, D., REZENDE, C.A.F., TIESENHUSEN, I.V., et al. Niveis de concentrado e silagem de capim na engorda de novilhas em confinamento. In: REUNIÃO ANUAL SOCIEDADE BRASILEIRA DE ZOOTECNIA, 1990, Campinas, SP. Anais ... Campinas, Sociedade Brasileira de Zootecnia, 1990, p. 47, 813 p. 